\title{
A unilateral memory defect ${ }^{1}$
}

\author{
KENNETH M. HEILMAN, ROBERT T. WATSON, \\ AND HOWARD M. SCHULMAN
}

From the Section of Neurology and Department of Clinical Psychology, University of Florida, College of Medicine, and the Veterans Administration Hospital, Gainesville, Florida, U.S.A.

SYNOPSIS Several authors have suggested that arousal is an important component of learning. If the neglect syndrome is a unilateral defect of alerting (arousal) as recent studies have suggested, then patients with this syndrome should have a unilateral learning defect. To test these hypotheses, eight patients with unilateral neglect were given consonant trigrams randomly to either ear, and the patients were asked to identify the auditory stimuli either immediately or after an 18 second delay during which time the patients were asked to count. All eight demonstrated that the number of errors between the delay and non-delay conditions was greater on the neglected side (significance $>0.01$ ), thereby supporting these hypotheses.

A recent study suggests that an attentional defect may be the basis of the neglect syndrome (inattention, hemispatial agnosia, extinction) (Heilman and Valenstein, 1972a; Watson et al., $1973 a, b)$. This attentional defect has been defined as a unilateral defect in the alerting (arousal) response to sensory stimuli(Watson et al., 1973a).

William James (1890) noted 'that an object once attended to will remain in the memory whilst one inattentively allowed to pass will leave no traces behind'. More recently, Sokolov (1960, 1963) and Magoun (1969) have also suggested that alerting is an important component of learning. If neglect is a unilateral defect in alerting and alerting is important in learning, then one would expect a patient with unilateral neglect to have unilateral learning disorders. The purpose of the study was to test this hypothesis.

\section{METHODS}

Subjects for this study were eight patients from the Neurological Division of the University of Florida Shands Teaching Hospital and Veterans Administration Hospital, Gainesville, Florida. Only patients who were tested for and demonstrated auditory neglect were included. Auditory neglect in the study was assessed by several bedside methods of unilateral

\footnotetext{
1 Supported by Grant NIH-NS-10408.
}

and bilateral simultaneous stimulation (Bender and Diamond, 1961; Heilman and Valenstein, 1972b) $\stackrel{\odot}{\circ}$ Patients were given a unilateral stimulus to each ear尺 음 If they were able to hear the stimuli, they were given $\rightarrow$ stronger stimuli in a random fashion to either the right, left, or both ears. If a patient were consistentlyo able to identify unilateral stimuli but consistentlye missed one side with bilateral stimuli, he was con sidered to have auditory neglect. Three of these patients had infarction of their non-dominant cerebral hemisphere and one had cerebritis of her non-dominant parietal lobe. Two patients had tumours. One had metastatic disease to her nondominant frontal lobe, and the other had an astrocytoma of his non-dominant parietal lobe. One patient had trauma to his non-dominant hemisphere, and one patient had non-dominant hemisphere dysfunction of unknown aetiology with seizures.

PROCEDURE Thirty-two consonant trigrams - that is, JQW-of less than $21 \%$ association value (Witmer, 1935) were given randomly to either right or left ear. These 96 letters were delivered from a Revox tape recorder deck via Sony DR-7A headphones. The subject's task was to identify the auditory stimuli immediately after presentation (nondelay) or after a delay of 18 seconds during which time the subjects were requested to count (Peterson and Peterson, 1959). These 32 consonant trigrams and procedures were repeated to each subject with the earphones reversed and the initial earphone position was alternated with each subject. The delay 
TABLE

DIFFERENCE BETWEEN NUMBER OF ERRORS IN DELAY AND NON-DELAY CONDITIONS

\begin{tabular}{|c|c|c|c|c|c|c|c|c|}
\hline \multirow[t]{2}{*}{ Patient } & \multirow{2}{*}{$\begin{array}{l}\text { Neglected } \\
\text { side }\end{array}$} & \multicolumn{2}{|c|}{ Errors non-delay } & \multicolumn{2}{|c|}{ Errors delay } & \multicolumn{2}{|c|}{$\begin{array}{c}\text { Difference in errors } \\
\text { delay-non-delay }\end{array}$} & \multirow{2}{*}{$\begin{array}{c}\text { Difference of errors } \\
\text { (delay-non-delay) } \\
\text { between sides } \\
\text { (neglected side- } \\
\text { non-neglected side) }\end{array}$} \\
\hline & & $\begin{array}{l}\text { Neglected } \\
\text { side }\end{array}$ & $\begin{array}{c}\text { Non-neglected } \\
\text { side }\end{array}$ & $\begin{array}{l}\text { Neglected } \\
\text { side }\end{array}$ & $\begin{array}{l}\text { Non-neglected } \\
\text { side }\end{array}$ & $\begin{array}{l}\text { Neglected } \\
\text { side }\end{array}$ & $\begin{array}{c}\text { Non-neglected } \\
\text { side }\end{array}$ & \\
\hline $\begin{array}{l}1 \\
2 \\
3 \\
4 \\
5 \\
6 \\
7 \\
8\end{array}$ & $\begin{array}{l}\mathbf{L} \\
\mathbf{R} \\
\mathbf{R} \\
\mathbf{L} \\
\mathbf{L} \\
\mathbf{L} \\
\mathbf{L} \\
\mathbf{L}\end{array}$ & $\begin{array}{r}1 \\
3 \\
1 \\
3 \\
2 \\
0 \\
4 \\
11\end{array}$ & $\begin{array}{r}0 \\
0 \\
1 \\
7 \\
0 \\
0 \\
3 \\
19\end{array}$ & $\begin{array}{l}35 \\
21 \\
21 \\
11 \\
36 \\
33 \\
37 \\
19\end{array}$ & $\begin{array}{r}23 \\
2 \\
17 \\
8 \\
30 \\
27 \\
30 \\
12\end{array}$ & $\begin{array}{r}34 \\
18 \\
20 \\
8 \\
34 \\
33 \\
33 \\
8\end{array}$ & $\begin{array}{r}23 \\
2 \\
16 \\
1 \\
30 \\
27 \\
27 \\
-7\end{array}$ & $\begin{array}{r}11 \\
16 \\
4 \\
7 \\
4 \\
5 \\
6 \\
15\end{array}$ \\
\hline
\end{tabular}

and non-delay conditions were also selected randomly.

ANALYSIS OF DATA If a patient missed consonants in the non-delay condition, we considered that there was either a defect in hearing, attention, or perception. Since the stimuli were the same for delay and non-delay conditions, the difference between the number of errors in these conditions should reflect what is lost going to short-term memory. If this difference is higher in the ear on the side with neglect than it is in the side without neglect, it would suggest that there is a defect in memory associated with neglect.

\section{RESULTS}

In the non-delay condition there was no significant difference between the ears. All eight subjects showed that the difference in the number of errors (between the delay and non-delay conditions) was greater on the neglect side. This was significant at the 0.004 level (Table) using a binomial test.

\section{DISCUSSION}

Butters et al. (1970) assessed patients with right hemisphere damage to ascertain if there were a
Primary somaesthetic<smiles>[3H]C</smiles>

Somaesthetic association

\section{Primary visual}

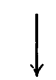

Visual association
Primary auditory<smiles>[3H][CH]</smiles>

Auditory association

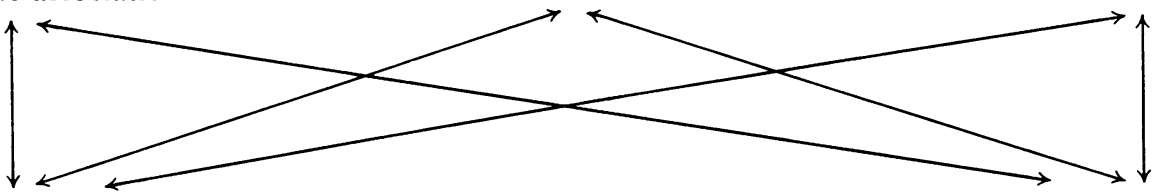

Parietal confluence

Frontal confluence (arcuate gyrus)
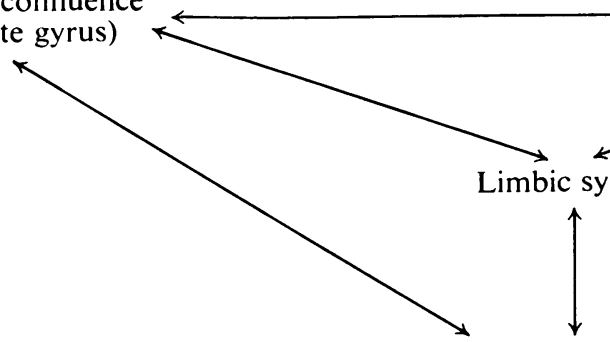
(inferior parietal lobule)

Reticular activation system

FIGURE Corticolimbic-reticular formation loop. 
visual or auditory memory defect associated with these lesions using the Peterson-Peterson (1959) procedure, which permitted separation of the perceptual and memory components. They found that there was a visual memory defect; however, they did not find a memory defect for auditory stimuli. This suggested to the authors 'that the deficit of the right parietal group is not a general memory impairment but rather one restricted to the storage of visually presented material'.

The mechanism for this memory disorder is not readily apparent. It is known, however, that lesions which occur in the right parietal lobe are frequently associated with the syndrome of neglect. It has been hypothesized that unilateral neglect is a unilateral defect of alerting caused by a corticolimbic reticular activating disconnection (Heilman and Valenstein, 1972a; Watson et al., 1973a). Partial support of this hypothesis comes from anatomical and ablative studies. In monkeys it has been shown that primary sensory areas project to their association cortex, then to the arcuate gyrus in the frontal lobe and to the inferior parietal lobule and the posterior portions of the superior temporal gyrus (Pandya and Kuypers, 1969). These, in turn, project to the cingulate gyrus (and perhaps other portions of the limbic system) which has extensive connection with the mesencephalic reticular formation (Nauta, 1964) (Figure). Lesions in the frontal lobes in both man (Heilman and Valenstein, 1972a) and monkey (Welch and Stuteville, 1958), and parietal lesions in man (Critchley, 1953; Heilman and Valenstein, 1972b) and monkey (Heilman et al., 1970; Eidelberg and Schwartz, 1971) have produced neglect. In addition, lesions of the cingulate gyrus (Watson et al., 1973a) and mesencephalic reticular formation (Watson et al., 1973b) also produce neglect. These lesions all have something in common: they all are capable of producing disconnection of the corticolimbic reticular activating system. Electrophysiological studies give further support to the arousal hypothesis. French et al. (1955) stimulated different parts of the cortex while recording from the reticular activating system. The areas which showed cortifugal projections to the reticular activating system were the same as those causing neglect when ablated. In addition, the discrete lesions in the mesencephalic reticular formation which produces profound neglect causes diffuse electroencephalographic (EEG) slowing in both cats (Reeves and Hagamen, 1971) and monkeys (Watson et al., 1973b). Cortical lesions which produce neglect are also with diffuse EEG changes both in man (Heilman et al., 1973) and cats (Reeves and Hagaman, 1971).

If we accept the hypothesis that unilateral neglect is a unilateral defect in alerting, what then is the relationship between attention and learning? Support for the hypothesis that attention is not only important for perception but is also important for memory comes from the studies of Norman (1969) who asked patients to repeat what they heard as soon as they heard it from one ear (shadowing). For perfect shadowing, attention must be paid to one ear. In this task another message is simultaneously being given to the other ear. Usually little or nothing is remembered of the non-shadowed message. To determine if the non-shadowed message is perceived and remembered briefly before the 'trace disappears', Norman interrupted subjects while they were shadowing and quickly demanded of them what they heard in the non-shadowed ear and found that the traces was present.

Alerting appears to be mediated by the reticular activating system which has been thought by some to be an amplifying system (Sokolov, 1960). This amplifying system increases cortical excitability (Sokolov, 1960), increases discriminating power (Lynn, 1966), and therefore probably enhances learning. Further support that arousal is important for learning comes from studies which show that learning is facilitated by stimulatory drugs (Lashley, 1916; Irwin and Benuazizi, 1966) and by stimulation of the reticular activating system (Zuckermann, 1959; Irwin and Benuazizi, 1966).

A major discrepancy between Butters et al.'s study (1970) and this report is that they found no auditory memory defect in patients with right hemispheric lesions. There are two possible reasons. First, they presented their auditory stimuli in a free field and therefore could not compare one side with the other. Secondly, although neglect is frequently polymodal-that is, visual, auditory, somaesthetic-it is not necessarily so and, while our patients had 
auditory neglect, we are not certain that their patients demonstrated auditory neglect.

Kimura (1963) and Milner (1962, 1967, 1968) have reported that memory storage in the temporal lobe is differentiated not by sensory modality but by the type of material being stored-that is, verbal on the left and spatial on the right. Samuels et al. (1971a) compared the patients with cortical brain damage studied by Butters et al. (1970) and compared these patients with patients with Korsakoff's syndrome. She found that the visual memory defect was similar in both groups and that the major difference was that the cortical group (non-limbic) had a defect which was modality specific (visual). Our study suggests that the defect is not modality specific and therefore the differentiation made by Samuels et al. (1971a) is not valid. However, we do feel that there is a difference between our patients and those with Korsakoff's syndrome on one hand and patients with temporal lobe ablations on the other. Unlike the Korsakoff and temporal lobectomy patients, our patients have a memory defect which is asymmetrical and affects mainly those stimuli coming in on the side with neglect. Support for this observation comes from an additional paper by Samuels et al. (1971b) in which they performed further analysis on their data and showed that the visual memory defect was worse in the contralateral field.

\section{REFERENCES}

Bender, M. B., and Diamond, S. P. (1965). An analysis of auditory perceptual defects with observations on the localization of dysfunction. Brain, 88, 675-686.

Butters, N., Samuels, I., Goodglass, H., and Brady, B. (1970). Short-term visual and auditory memory disorders after parietal and frontal lobe damage. Cortex, 6, 440-549.

Critchley, M. (1953). The Parietal Lobes. Arnold: London. (Reprinted by Hofner: New York, 1966.)

Eidelberg, E., and Schwartz, A. S. (1971). Experimental analysis of the extinction phenomenon in monkeys. Brain, 94, 91-108.

French, J. D., Hernandez-Peon, R., and Livingston, R. B. (1955). Projections from cortex to cephalic brain stem (reticular formation) in monkey. Journal of Neurophysiology, 18, 74-95.

Heilman, K. M., Musella, L., and Watson, R. T. (1973). The EEG in neglect. (Abstract.) Neurology (Minneap.), 23, 437.

Heilman, K. M., Pandya, D. N., and Geschwind, N. (1970). Trimodal inattention following parietal lobe ablations. Transactions of the American Neurological Association, 95, 259-261.

Heilman, K. M., and Valenstein, E. (1972a). Frontal lobe neglect in man. Neurology (Minneap.), 22, 660-664.

Heilman, K. M., and Valenstein, E. (1972b). Auditory neglect in man. Archives of Neurology, 26, 32-35.
Irwin, S., and Benuazizi, A. (1966). Pentylenetetrazol enhances memory function. Science, 152, 100-102.

James, W. (1890). The Principles of Psychology. 2 Vol. Holt: New York.

Kimura, D. (1963). Right temporal-lobe damage. Archives of Neurology, 8, 264-271.

Lashley, K. S. (1917). The effects of strychnine and caffeine upon rate of learning. Psychobiology, 1, 141-169.

Lynn, R. (1966). Attention, Arousal and the Orientation Reaction. Pergamon Press: Oxford.

Magoun, H. W. (1969). On the biology of learning. In Advances in Brain Research with Implication for Learning. Edited by K. H. Pribram. Harcourt, Brace, and World: New York.

Milner, B. (1962). Laterality effects in audition. In Interhemispheric Relations and Cerebral Dominance, pp. 177195. Edited by V. B. Mountcastle. Johns Hopkins Press: Baltimore.

Milner, B. (1967). Brain mechanisms suggested by studies of temporal lobes. In Brain Mechanisms Underlying Speech and Language, pp. 122-145. Edited by F. L. Darley. Grune and Stratton: New York.

Milner, B. (1968). Visual recognition and recall after right temporal-lobe excision in man. Neuropsychologia, 6, 191209.

Nauta, W. J. H. (1964). Some efferent connections of the prefrontal cortex in the monkey. In The Frontal Granular Cortex and Behavior, pp. 397-409. Edited by J. M. Warren and K. Akert. McGraw-Hill: New York.

Norman, D. A. (1969). Memory and Attention. Wiley: New York.

Pandya, D. N., and Kuypers, H. G. J. M. (1969). Corticocortical connections in the rhesus monkey. Brain Research, 13, 13-36.

Peterson, L. R., and Peterson, M. J. (1959). Short-term retention of individual verbal items. Journal of Experimental Psychology, 58, 193-198.

Reeves, A. G., and Hagamen, W. D. (1971). Behavioral and EEG asymmetry following unilateral lesions of the forebrain and midbrain in cats. Electroencephalography and Clinical Neurophysiology, 30, 83-86.

Samuels, I., Butters, N., Goodglass, H., and Brody, B. (1971a). A comparison of subcortical and cortical damage on short-term visual and auditory memory. Neuropsychologia, 9, 293-306.

Samuels, I., Butters, N., and Goodglass, H. (1971b). Visual memory deficits following cortical and limbic lesions: effect of field of presentation. Physiology and Behavior, 6, 447-452.

Sokolov, E. N. (1960). Neuronal models and the orienting reflex. In The Central Nervous System and Behavior, pp. 187-276. Edited by M. A. B. Brazier. Josiah Macy Jr Foundation: New York.

Sokolov, E. N. (1963). Perception and the Conditioned Reflex. Pergamon Press: Oxford.

Watson, R. T., Heilman, K. M., Cauthen, J. C., and King, F. A. (1973a). Neglect following cingulectomy. Neurology (Minneap.), 23, 1003-1007.

Watson, R. T., Heilman, K. M., Miller, B. D., and King, F. A. (1973b). Neglect following mesencephalic reticular formation lesions. (Abstract.) Neurology (Minneap.), 23, 395.

Welch, K., and Stuteville, P. (1958). Experimental production of unilateral neglect in monkeys. Brain, 81, 341-347.

Witmer, L. R. (1935). The association value of three-place constant syllables. Journal of Genetic Psychology, 47, 337359.

Zuckermann, E. (1959). Effect of cortical and reticular stimulation on conditioned reflex activity. Journal of Neurophysiology, 22, 633-643. 